\title{
СОЦИОЛОГИЯ КОММУНИКАЦИЙ
}

М.Г. Кочетова, канд. филол. наук, доц., зав. кафедрой английского языка для гуманитарных факультетов факультета иностранных языков и регионоведения МГУ имени М.В. Ломоносова*

\section{СОЦИАЛЬНО-КУЛЬТУРНЫЙ АСПЕКТ ЛИНГВИСТИЧЕСКОЙ ВАРИАТИВНОСТИ: ВЗГЛЯД ИЗНУТРИ}

\section{M.G. Kochetova \\ SOCIAL AND CULTURAL ASPECTS OF LANGUAGE VARIATION: VIEW FROM THE INSIDE}

В процессе интервью представителей различных групп англоязычного населения была выяснена ситуация с вариативностью в современном английском языке. Носители английского языка способны переходить с одного варианта языка на другой в зависимости от социокультурного контекста. В некоторых случаях он предполагает нормативность форм выражения, в других - использование диалектов. Опрошенные в целом толерантно относятся к языковой вариативности, однако подсознательно “дают оценку” своему собеседнику.

Ключевые слова: интервью, английский язык, социально-культурный, вариативность, норма.

Different groups of English-speaking population were interviewed. They discuss current situation with variability of English. Speakers of English can shift dialects according to social and cultural context. Some contexts imply the use of Standard English, others - dialects. The interviewed accept freedom of expression but they make judgments of those who misuse English.

Key words: interview, English, social, cultural, variation, Norm.

Данное социально-лингвистическое исследование посвящено вопросу вариативности в современном английском языке. Актуальность этой проблематики подтверждается наличием в нем большого количества различных вариантов, допустимых в речи, но не занесенных в учебники по грамматике, а также наличием ряда ненормативных форм, присутствующих в речи носителей языка, но являющихся при этом диалектно окрашенными.

С педагогической точки зрения представляется необходимым попытаться как можно точнее определить грань между вариатив-

\footnotetext{
* Кочетова Мария Германовна, e-mail: mkochetova@yahoo.com
} 
ными формами в пределах нормы и вне ее и так называемыми “злоупотреблениями”, особенно если учитывать вопросы межнационального общения и преподавания английского языка как средства международного общения. А в социокультурном плане представляется интересным выяснить отношение носителей английского языка к его вариантам.

Теории английского языка посвящено множество книг и пособий. Но свидетельства участника некоторого процесса (в данном случае языкового), возможно, более эффективно, нежели теоретизирование на основе одних лишь печатных изданий. Поэтому в рамках данного исследования было интересно выяснить, что происходит с языком внутри социально-лингвистической среды его носителей, как и в какой степени их речь отличается от того грамматического стандарта, которому учат в школе, какие варианты они могут допустить, а какие - вызывают у них отрицательное отношение. Таким образом, была сделана попытка определить, какие тенденции реально имеют место в живом, находящемся в постоянном движении и развитии современном английском языке, какого языкового проявления можно ожидать в конкретной социальнокультурной среде, и какую оценку дают грамотные слушатели носителям ненормативных вариантов. Также была сделана попытка выяснить, как относятся носители диалектов к языковой норме и носителям этой нормы.

В процессе данного социально-лингвистического исследования автором был взят ряд очных интервью у представителей различных групп англоязычного населения. Среди опрошенных особый интерес вызвали несколько человек. Первый - это Лори Рэнтала (Lauri Rantala), известный американский театральный критик, журналист газеты "Chicago Tribune", автор книги о печально знаменитом американском футболисте и актере O.J. Simpson-e: “O.J. Unmasked: the trial, the truth, and the media"1. Еще один участник интервью, мнение которого, без сомнения, заслуживает внимания, - это Марчелло Черчи (Marcello Cherchi, M.D., Ph.D.), врач, профессор медицины в области клинической неврологии и патологии языка, по образованию также лингвист, имеет степень Ph.D. в области лингвистики. Он является не только грамотным носителем английского языка, но и изучает его с профессиональной точки зрения ${ }^{2}$.

Несомненный интерес среди опрошенных представляет еще один участник данного исследования - Маргарет Морган (Margaret Morgan), молекулярный биолог и генетик из Австралии, работающая

${ }^{1}$ Cм.: Rantala M.L. O.J. Unmasked: the trial, the truth, and the media (Paperback). Open Court, 1999.

${ }^{2}$ CM.: Cherchi M. Challenges in the investigation of cerebral function: neuroanatomical substrates of language processing. Munich; Newcastle, 2000. 
в Чикагском университете (University of Chicago). Интересными с лингвистической точки зрения оказались два афроамериканца носители диалекта эбоникс, интервью у которых было взято на улице города Чикаго. Таким образом, при выборе участников эксперимента был сделан условный срез англоязычного общества и проанализировано отношение разных групп населения к вариативности в языке, в частности к таким явлениям, как языковая норма и отклонения от нее.

Как показал опрос, понятие “норма” оказалось для всех общим, a ее источником для всех были школьные учителя и школьные учебники, а также справочники по грамматике. Таким образом, на практике грамматическая норма - это свод правил, закрепленных в учебниках и учебных пособиях. Например, среди прочего был упомянут "Chicago manual of style". При этом все опрошенные неоднократно отмечали, что язык находится в постоянном развитии ("it fluctuates, it changes, it grows"), а языковая норма - это теория, существующая главным образом на бумаге. Тем не менее, она есть и представляет собой некоторый образец, от которого отталкиваются носители языка в своем вербальном проявлении. Грамотные носители языка о ней (ее) знают, но не всегда ей следуют, особенно если это касается его устной формы.

В письменной форме речи следование норме, естественно, более строгое, чем в устной. Опрошенные отмечали, что когда они пишут, то стараются придерживаться определенных грамматических правил и, что немаловажно, ожидают этого от других. Письменный язык предоставляет меньше свободы в выборе языковых форм. Однако в устной речи правила не так существенны, у всех есть свои индивидуальные особенности выражения, свой стиль, с которым участники исследования в свете свободы слова и волеизъявления принципиально считаются. Они, как правило, терпимо относятся к проявлению индивидуальности, тем более что “быть собой” сейчас как никогда современно и даже модно. Однако, как известно, все хорошо в меру, и злоупотребление ненормативным языком может вызвать отрицательные эмоции. В целом участники исследования не испытывают негативного отношения к дискретным отступлениям от нормы в процессе межкультурной коммуникации, хотя отмечают про себя случаи ее “нецелевого" использования. Все зависит от конкретной ситуации. Игнорирование грамматики образованным человеком или использование сленга, например, университетским профессором, выглядит по меньшей мере странно. Существуют определенные обстоятельства, определенная социально-культурная среда, при которых и в которой следование грамматической норме считается признаком образованности, интеллигент- 
ности и хорошего тона. В академической среде или, например, в театральной среде говорящий будет стараться избегать ненормативных оборотов и вариантов и стараться следовать норме, потому что “в этом обществе так принято”.

Все опрошенные сходятся во мнении, что не только образование человека играет роль в том, насколько правильно он говорит на родном языке, но также место, где он родился и вырос, окружение, которое оказывало или оказывает на него влияние.

Это в полной мере подтвердили и два афроамериканских участника эксперимента, которые вопреки ожиданию услышать из их уст афроамериканский диалект английского языка при разговоре перешли с родного варианта эбоникс на вариант очень близкий к стандартному. Несмотря на то что они не смогли практически ничего сказать о грамматике, кроме “Да, это важно" ("Yeah, it's important", что, впрочем, неудивительно, так как в процессе беседы выяснилось, что ее изучению они посвятили очень мало времени), их язык был понятен, и говорили они простыми короткими фразами. Это произошло из-за того, что они оказались в иной социолингвистической среде, им были заданы серьезные вопросы и надо было говорить на научную тему. Следовательно, эти люди теоретически знали, как надо говорить на стандартном варианте английского языка, и легко на него перешли.

Маргарет Морган привела интересный пример. Летом в Чикагском университете проходила практику чернокожая американка. Она говорила так, как говорят все афроамериканцы ("She is black and talks like a black person"). Она использовала в своем языке сленг и, как сказала Маргарет Морган, “очень много грамматически неправильных конструкций”, однако это имело место только в разговоре с чернокожими американцами. В разговоре с белыми коллегами из лаборатории она использовала в речи только нормативные варианты. Отлично владея своим родным языком, она приспосабливала его к определенной ситуации речи, варьируя речевым выражением. Из сказанного можно сделать вывод, что при выборе языкового варианта определяющим является не только образование человека, но и социально-культурный контекст.

В настоящее время установлено, что носители английского языка владеют стандартным вариантом английского языка или, по крайней мере, имеют представление как о своем диалекте, так и о стандартном варианте. Возможно также владение и некоторыми другими вариантами, если от них этого требует социокультурный контекст. Об этом свидетельствует способность говорящего сознательно переходить с одного варианта на другой (“to shift styles”) ${ }^{3}$.

${ }^{3}$ Cм.: Wolfram W.A. Dialects in Americam English. Englewood Cliffs, 1991. P. 139-141. 
Однако, как отмечает П. Традгилл и как показало данное исследование, часто пассивная компетентность превалирует над активной ${ }^{4}$.

На вопрос “Кто употребляет в своей речи ненормативный язык (non-standard English)?” был дан ответ, что в большей или меньшей степени это делают все. Но те, кто это делает, могут быть разделены на две группы. Первую группу составляют малообразованные люди, которые выросли в среде, где “все так говорят”. Как правило, это люди из бедных районов, часто это афроамериканцы - носители варианта эбоникс или малообразованные выходцы из сельских или рабочих районов Европы или Австралии. Для данной категории, по мнению опрошенных носителей английского языка, особенно характерно:

- двойное отрицание (double negatives), которое часто встречается в диалектах и пользуется особой популярностью среди афроамериканского населения в целом (“I don’t know nothing”, “I did not kill nobody");

- опущение окончания -s c глаголами настоящего времени в третьем лице и единственном числе (“It don't matter”, “He always act this way");

- использование несуществующей в стандартном языке формы местоимения второго лица yous для выражения множественного числа (“Yous, guys, look really good”), формы y'all и других ненормативных вариантов;

- опущение вспомогательных глаголов (“They fine”);

- некоторые другие ненормативные грамматические формы;

- широкая вариативность в области лексики и фонетики: употребление диалектных форм речи, сленга, выбор языковых форм, не характерных для стандартного языка.

Вторую группу составляют образованные люди, которые знают, как надо говорить правильно, но по некоторым причинам употребляют ненормативные варианты, главным образом - ненормативные грамматические варианты.

Анализируя различные ситуации, участники проведенного исследования выделили следующие причины ненормативного лингвистического поведения среди грамотных носителей языка:

- неосознанное воспроизведение ненормативной формы: "Where's the books?" вместо "Where are the books?" или "Here's the books" вместо "Here are the books". "How's things?" вместо "How are things?" В своих комментариях участники опроса поясняют, что они знают, как говорить правильно, но в устной речи им, например, нравится

${ }^{4}$ Cм.: Trudgill P. On dialect: social and geographical perspectives. N.Y.; L., 1984. P. 10. 
говорить “where's”, “there's”, “here's”, “how is” с последующим существительным во множественном числе (Марчелло Черчи). Вероятнее всего, в данном случае мы имеем дело с воздействием фонетических процессов на грамматику и так называемым явлением “экономии усилия". Еще одним возможным объяснением появления данных ненормативных форм может служить влияние диалектов на языковую норму. Можно предположить так называемую языковую интерференцию и, как результат, свободный выбор носителем языка “более звучащего” варианта из двух возможных:

- стилистическое использование ненормативной грамматики является намеренным и находится в области эмоционально окрашенной речи или поэтики. Здесь особую роль приобретает изменение порядка слов и синтаксической организации высказывания: "A real perfectionist he was!", "Here she comes!” Как в поэзии, так и в прозе отступления от норм коллигации и коллокации многочисленны. Этот прием широко используется и в рекламе. Маргарет Морган в этой связи привела в качестве примера рекламу авиалиний: "We gonna fly you where you wanna go".

- намеренное отступление от стандарта, языковая мимикрия. Не желая подчеркивать свою идеальную грамотность и университетское образование в среде людей, не имеющих такового, образованные люди часто испытывают необходимость говорить на языке, типичном для данного круга собеседников. Эта тенденция особенно характерна как для многонационального американского общества, так и для британского и австралийского. Существуют контексты, когда отступление от стандарта используется с целью быть принятым в определенной социальной среде ${ }^{5}$.

Лори Рэнтала, журналист по профессии, упомянула в этой связи свой личный опыт. Она была свидетелем выступления Джорджа Буша с предвыборной речью на партийном съезде. В его речи не было грубых ошибок или ненормативных вариантов, но в целом она была далека от языкового стандарта. Он, имея высшее образование, старался не говорить как грамотный образованный человек, принадлежащий к высшему обществу. Он говорил как малообразованный человек, и таковым, с подачи журналистов, транслирующих его речи, его знают: косноязычным и якобы малограмотным. И именно так, по словам Лори, поступают многие политики. С целью преподнести себя избирателям как “одного из них" они намеренно отступают от языковой нормы, приближая свою речь к тому языковому варианту, на котором говорит их электорат.

${ }^{5}$ См.: Кочетова М.Г. Социальные предпосылки грамматической вариативности // Вестн. Моск. ун-та. Сер. 19. Лингвистика и межкультурная коммуникация. 2002. № 3. C. $30-38$. 
Маргарет Морган отметила, что в Австралии наблюдается существенная разница между тем, на каком английском языке говорят в городах и на каком - в сельской местности. В речи людей со средним образованием с большой степенью вероятности будут наблюдаться отклонения от языковой нормы. Кроме того, часто они относятся с недоверием, если не с предубеждением, к грамотной речи людей с высшим образованием, считая правильность речи признаком высокомерия. Поэтому в общении с такими людьми Маргарет Морган часто сама намеренно отходит от языковой нормы (и так, по ее словам, поступают многие), используя в речи сленг. В таком случае люди чувствуют себя более комфортно, пребывая во время беседы с ней в знакомой социолингвистической и культурной среде.

Таким образом, следование норме или употребление ненормативных форм определяется не только уровнем образованности конкретного человека, но также той социально-культурной средой, в которой он находится в конкретный момент времени.

Перефразируя известную русскую пословицу, можно сказать следующее: “Начни говорить, и я скажу, кто ты”. О человеке судят по тому, как он говорит, какие фразы выбирает, какой лексикой пользуется, следует или нет правилам грамматики. Грамотные носители языка во время интервью неоднократно это отмечали. Несмотря на толерантное отношение к отступлениям от языковой нормы, они тем не менее подсознательно “дают оценку” своему собеседнику.

Очевидно, что ряд ненормативных форм тяготеют к норме и постепенно могут стать ее частью. Однако здесь необходимо сделать некоторое уточнение и определить, что значит "тяготеют к норме”. В современном английском языке существует ряд вариантов, которые в силу внутренних процессов, происходящих в нем, стали настолько общеупотребимы, что даже грамотные носители языка не всегда могут уверенно судить о нормативности определенного варианта. Лори Рэнтала привела пример лексической вариативности, когда очень многие, по ее мнению, американцы используют слова "comprise" и "compose" как синонимы. Подобная вариативность часто встречается в устной речи, но в письменной ее нет. Поэтому, прежде чем отдать свою статью редактору газеты "Chicago Tribune" на просмотр, ей иногда приходится обращаться к справочникам по грамматике, так как она не знает точно, какой вариант нормативный, а какой - только разговорный. Письменный язык тяготеет к языковому образцу, языковой норме, и письменная речь, особенно крупных печатных изданий, таким образом, требует редакторской правки для максимального к ней приближения. 
Интересно отметить, что один из опрошенных мною американцев, родившийся и всю жизнь проживший на Среднем Западе США, получивший высшее образование, не всегда понимает, что говорят люди из других штатов, например из Вирджинии или Кентукки. А Маргарет Морган, австралийка по происхождению, прожившая большую часть жизни в Австралии и получившая там высшее образование, понимает лишь часть того, что говорят жители ее страны - носители английского языка из сельских районов. Произношение отдельных звуков или их сочетаний может различаться, различен выбор слов и оборотов, существенно различается фразеология, однако, как заметили некоторые участники интервью, главенствующую роль играет именно грамматика, вызывающая определенные проблемы и недопонимание. Контакт в таких ситуациях устанавливается путем переспроса и перефразирования.

Было бы неправильным рассматривать языковые варианты (именно варианты, а не ошибки неграмотного человека), как плохие или хорошие, правильные или неправильные. В данном контексте интересно привести мнение известного филолога Л.П. Смита. Он неоднократно отмечал своеобразную природу некоторых ненормативных форм. Речь в данном случае идет не о явных отклонениях от правил, что справедливо считается ошибкой и чего намеренно избегают образованные носители языка даже в устной речи, а о ненормативных вариантах, повсеместно встречающихся в речи даже грамотных носителей английского языка. Эти небольшие “неправильности”, как пишет Л.П. Смит, несомненно, имеют определенную ценность и выразительность: “Они могут быть сравнимы с незначительными изъянами, придающими обладателю ими неповторимый шарм" 6 . "Полагать, что диалекты - суть только искажения литературного языка, было бы ошибочно. Диалекты всегда были для литературного языка скорее питающими притоками, нежели отводящими рукавами или каналами"7.

Однако не вызывает сомнения тот факт, что отношение к ненормативным вариантам английского языка у разных людей бывает разным. Это может быть связано как с определенным историческим этапом развития языка, с общими тенденциями в общественной и политической жизни, так и с уровнем социальной терпимости к различным проявлениям индивидуальности на разных этапах этого развития. Поэтому лингвистические варианты полезно знать, но при этом необходимо четко понимать, когда, где и кем они могут употребляться.

\footnotetext{
${ }^{6}$ См.: Смит Л.П. Фразеология английского языка. М., 1959. С. 24-26.

${ }^{7}$ См.: Чикобава А.К. Проблема языка как предмета языкознания. М., 1959. С. 58.
} 
Основные выводы и практические рекомендации, которые можно дать на основании проведенного социально-лингвистического исследования, заключаются в следующем. Даже в пределах одного государства взаимное понимание опирается на вариант языка, понятный всем участникам коммуникации, т.е. на норму, какой бы подвижной она ни была на данный момент.

Несмотря на существование ненормативных лингвистических вариантов в языке (даже в речи грамотных его носителей), при обучении иностранному языку необходимо понимать, что хотя эти варианты существуют, их употребление вне соответствующей социолингвистической ситуации и ожидаемого контекста считается неуместным, выглядит странно и при всей толерантности общества к индивидуальным вербальным проявлениям в целом не вызывает одобрения со стороны носителей английского языка.

Таким образом, роль языковой нормы неоспорима. В процессе общения мы всегда “опознаем” и оцениваем говорящего по его речи, поэтому важно, чтобы обучение языку основывалось на социально-нейтральных грамотных формах выражения, а значит на стандартном варианте английского языка, зафиксированном в учебниках и учебных пособиях.

\section{СПИСОК ЛИТЕРАТУРЫ}

Кочетова М.Г. Социальные предпосылки грамматической вариативности // Вестн. Моск. ун-та. Сер. 19. Лингвистика и межкультурная коммуникация. 2002. № 3 (Kochetova M.G. Social'nye predposylki grammaticheskoj variativnosti // Vestn. Mosk. un-ta. Ser. 19. Lingvistika i mezhkul'turnaja kommunikacija. 2002. N 3).

Cмит Л.П. Фразеология английского языка. М., 1959 (Smit L.P. Frazeologija anglijskogo jazyka. M., 1959).

Чикобава А.К. Проблема языка как предмета языкознания. М., 1959 (Chikobava A.K. Problema jazyka kak predmeta jazykoznanija. M., 1959).

Cherchi $M$. Challenges in the investigation of cerebral function: neuroanatomical substrates of language processing. Munich; Newcastle, 2000.

Rantala M.L. O.J. Unmasked: the trial, the truth, and the media (Paperback). Open Court, 1999.

Trudgill P. On dialect: social and geographical perspectives. N.Y.; L., 1984.

Wolfram W.A. Dialects in Americam English. Englewood Cliffs, 1991. 